EXTENDED REPORT

\title{
Anti-Ro/SSA and anti-La/SSB autoantibodies in the tear fluid of patients with Siögren's syndrome
}

\author{
E Toker, Ș Yavuz, H Direskeneli
}

Br J Ophthalmol 2004;88:384-387. doi: 10.1136/bjo.2003.028340

See end of article for authors' affiliations

\section{Correspondence to:} Professor E Toker, Inonu C Yildiz S, STFA Blokari B-6, D:13 Kozyatagi, Istanbul, Turkey; aetoker@ superonline.com

Accepted for publication 1 September 2003

\begin{abstract}
Purpose: To investigate the presence of anti-Ro/SSA and anti-La/SSB antibodies in the tear fluid and serum of patients with Siögren's syndrome and to evaluate the association of these autoantibodies with the severity of keratoconjunctivitis sicca.

Methods: Tear fluid and serum were obtained from 28 patients with Sjögren's syndrome and 17 age matched normal control subjects. Evaluation of tear fluid and sera anti-Ro/SSA and anti-La/SSB levels was done by using a quantitative enzyme linked immunosorbent assay kit designed for the quantitative measurement of $\lg G$ class autoantibodies directed against highly purified SSA and SSB antigens. Tear function and ocular surface were evaluated by Schirmer I test, tear break up time, and rose bengal staining. Dry eye symptom scores were recorded.

Results: Increased levels of anti-Ro/SSA and anti-La/SSB antibodies were detected in sera of $57.1 \%$ and $50 \%$ of SS patients, respectively. Six patients had increased levels of anti-Ro/SSA in the tear fluid, in one case anti-Ro/SSA being detected in tear fluid when it was negative in serum. Ten patients had positive anti-La/SSB titres in tear fluid and in four of these patients, anti-La/SSB titres were not elevated in serum. A positive correlation was observed between serum and tear fluid titres of anti-Ro/SSA ( $r=0.43, p=0.02)$, but not of anti-La/SSB. Serum anti-Ro/SSA and anti-La/SSB concentrations correlated positively with dry eye symptom scores $(r=0.42, p=0.02$ and $r=0.48, p=0.01$, respectively) and negatively correlated with Schirmer I test scores $(r=-0.39, p=0.04$ and $r=-0.40, p=0.03$, respectively). Significant correlations were found between tear anti-La/SSB concentrations and dry eye symptom score $(r=0.56, p=0.02)$ and also rose bengal staining scores of the ocular surface $(r=0.44, p=0.02)$.

Conclusion: This study shows that autoantibodies against Ro/SSA and La/SSB antigens are present in the tear fluid of some patients with SS and their presence in serum or tear fluid is associated with the severity of keratoconjunctivitis sicca. Additional measurement of tear fluid levels of anti-Ro/SSA and anti-La/SSB may serve as a valuable diagnostic indicator of SS.
\end{abstract}

$\mathrm{S}$ jögren's syndrome (SS) is considered to be the second most common disorder among the group of chronic systemic rheumatic diseases, exceeded only by rheumatoid arthritis. Exocrine glands are the principal target organs, but several non-exocrine organs may be affected as well. The immunopathological lesion of SS is characterised by mononuclear cell infiltrates around ductal and acinar epithelial cells of lacrimal and salivary glands, fibrosis, and gradual destruction of tissue architecture leading to severe dryness of eyes and mouth.

Autoantibodies to nuclear antigens occur in patients with multisystem autoimmune disease such as systemic lupus erythematosus, rheumatoid arthritis, and SS. Although heterogeneous, there are two major groups-autoantibodies to DNA and autoantibodies to non-DNA antigens-the latter including antinuclear antibodies to the soluble or "extractable nuclear antigens". Extractable nuclear antigens are ribonucleoproteins (RNPs) consisting of small ribonucleic acid (RNA) molecules attached to non-histone proteins and have three main categories: the U group comprising Ul-U6 small nuclear RNAs, the Ro group and the La group. The Ro/ SSA antigen is a small nucleocytoplasmic RNA protein complex. It consists of a $60 \mathrm{kDa}$ protein which is associated with one of four human cytoplasmic RNAs (hYl, hY3, hY4, hY5). ${ }^{1-3}$ Antibodies to a 52-kDa protein (anti-52-kDa Ro) are found in some sera with anti-60-kd $\mathrm{Ro}^{4}$ and association of this protein to the Ro RNP particle (60-kDa Ro plus hY RNA) remains a subject of controversy. ${ }^{5}{ }^{6}$ The functions of $60-\mathrm{kDa}$ Ro and 52-kDa Ro are not completely known, although 60$\mathrm{kDa}$ Ro may be involved in the ribosomal RNA discard pathway. ${ }^{7}$ The La/SSB antigen consists of a 48 -kDa protein ${ }^{8}$ and serves as a termination factor for RNA polymerase III. ${ }^{9}$

Presence of anti-Ro/SSA or anti-La/SSB autoantibodies is one of the classification criteria suggested by the European Community Study Group on diagnostic criteria for SS. ${ }^{11}$ AntiRo/SSA antibodies are present in sera of $50-70 \%$ of SS patients, while anti-La/SSB antibodies, which are more specific for SS can be detected $45-60 \% .^{12}$

Anti-Ro/SSA and anti-La/SSB antibodies have been demonstrated previously in the saliva of SS patients. ${ }^{13-15}$ In addition, anti-Ro/SSA and anti-La/SSB antibody producing cells were found in the labial salivary glands of SS patients. ${ }^{16}{ }^{17}$ However, the presence of these autoantibodies has not been studied in the tear fluid of patients with SS.

In this study, we investigated the presence of anti-Ro/SSA and anti-La/SSB antibodies in the serum and tear fluid of patients with SS to show whether local antibody measurements might be helpful in the diagnosis of SS. We also investigated whether the presence of these antibodies in serum or tear fluid is associated with the severity of keratoconjunctivitis sicca.

\section{Methods}

This comparative cross sectional study was performed at the Department of Ophthalmology of Marmara University Medical School. Peripheral blood and tear samples were

Abbreviations: RNA, ribonucleic acid; SS, Siögren's syndrome 
obtained from 28 female patients, aged between $21-78$ years (mean 56.9) with clinically definite SS. The patients were recruited from the Department of Rheumatology, Marmara University Medical School. Diagnosis of SS was made according to the criteria of the European Community Study Group. ${ }^{11}$ Briefly, the existence of at least four of the following six items is indicative of primary SS and the existence of item 1 or item 2 , plus any two from items 3,4, and 5 is indicative of secondary SS: (1) ocular symptoms, (2) oral symptoms, (3) ocular signs of KCS, (4) focal sialoadenitis by minor salivary gland biopsy, (5) objective evidence of salivary gland involvement, (6) presence of autoantibodies. Fourteen patients had primary SS and 14 had secondary SS. Of those with secondary SS, 12 had rheumatoid arthritis (RA) and two had systemic lupus erythematosus. Seventeen healthy females aged 32-70 years (mean 54.1) who had no symptoms of ocular irritation and had normal tear function were used as controls. The protocol for sample collection was approved by the institutional review board and all patients gave informed consent.

\section{Anti-Ro/SSA and anti-La/SSB assays}

Serum and tear fluid were obtained from SS patients and controls at the same visit. Blood was obtained by venous puncture and serum was separated by centrifugation. Ten $\mu \mathrm{l}$ tear fluid was collected from the lower cul de sac using blunt tip micropipettes. Samples were immediately frozen and stored at $-70^{\circ} \mathrm{C}$ until analysis. Concentrations of Ro/SSA and $\mathrm{La} / \mathrm{SSB}$ antibodies in serum and tear fluid samples were determined by the enzyme linked immunosorbent assay (ELISA) designed for the quantitative measurement of IgG class autoantibodies directed against highly purified SSA and SSB antigens (Genesis Diagnostics, Cambridgeshire, UK).

The values greater than mean $+2 \mathrm{SD}$ of anti-Ro/SSA and anti-La/SSB levels in healthy controls are defined as positive test results for SS patients.

\section{Subjective clinical assessment for dry eye}

SS patients were asked to complete a symptom questionnaire. Symptoms of dry eye, including dryness, burning, foreign body sensation, and blurred vision were graded by patients. Each symptom was scored $0-3$ according to severity $(0=$ none; $1=$ occasional and mild, not causing constant discomfort; 2 = moderate, causing constant discomfort, but no restriction on activities of daily living; $3=$ severe and constant with restriction of activities of daily living). The sum was recorded as total dry eye symptom score.

\section{Objective clinical assessments for dry eye}

Tear production was assessed by the Schirmer I test, in which the extent of tear flow down a piece of filter paper inserted into the lateral part of the inferior fornix of the eye is measured over a 5 minute period. Tear break up time was measured to assess tear film stability. Twenty five $\mu$ of $1 \%$ fluorescein solution was placed in the inferior fornix of each eye and the patients were asked to make 1-2 full blinks. Using a slit lamp, the interval between the last blink and the formation of growing black holes in the flourescinated tear fluid was measured by a stop watch. The ocular surface was examined by rose bengal staining. After placing $25 \mu \mathrm{l}$ of $1 \%$ rose bengal solution in the inferior fornix, the intensity of staining was recorded in the temporal and nasal conjunctiva and the cornea, each graded on a scale of 0 to 3 points (possible maximum total score of 9 ). ${ }^{18}$

\section{Statistical analysis}

The differences in autoantibody levels and clinical dry eye scores among study groups were determined by means of Kruskal-Wallis test. Associations between variables were analysed by Spearman's rank correlation test. A p value $<0.05$ was considered to indicate statistical significance.

\section{RESULTS \\ Detection of anti-Ro/SSA and anti-La/SSB antibodies in serum and tears}

The levels of anti-Ro/SSA and anti-La/SSB in serum and tear fluid of healthy controls and SS patients are shown in table 1 . The upper limits of (mean+2 SD) anti-Ro/SSA in serum and tear fluid in healthy controls were 27.1 and $25.2 \mathrm{U} / \mathrm{ml}$, respectively. The upper limits of (mean+2 SD) anti-La/SSA in serum and tear fluid were 31.2 and $31.1 \mathrm{U} / \mathrm{ml}$ respectively.

Sixteen of 28 SS $(57.1 \%)$ patients had increased levels of anti-Ro/SSA in serum and in five of these patients (4 primary SS $v$ l secondary SS) anti-Ro/SSA was also positive in tear fluid. In addition, one patient (primary SS) had elevated levels of anti-Ro/SSA in tear fluid without the presence of elevated anti-Ro/SSA in serum.

Fourteen of 28 SS (50\%) patients had increased anti-La/ SSB levels in serum. Ten patients ( 7 primary SS $v 3$ secondary SS) had positive anti-La/SSB titres in tear fluid and in four ( 3 primary SS $v$ l secondary SS) of these anti-La/SSB titres were not elevated in serum.

Positive correlations were found between serum levels of anti-Ro/SSA and anti-La/SSB $(r=0.74, \mathrm{p}<0.0001)$ and also between tear fluid levels of these autoantibodies $(r=0.48$, $\mathrm{p}=0.009)$.

A significant correlation was found between the serum and tear fluid levels of anti-Ro/SS-A in SS patients $(r=0.43$, $\mathrm{p}=0.02$ ) whereas the correlation between the serum and tear fluid levels of anti-La/SS-B was not significant.

\section{Correlation between clinical scores and autoantibody levels in serum and tear fluid}

The subjective and objective clinical dry eye scores of control subjects and patients with SS are shown in table 2 . The clinical dry eye scores of the control group were significantly different from either group of SS patients $(p<0.0001)$. No significant differences were observed between the dry eye scores of primary and secondary SS patients $(p>0.05)$.

Correlations between serum and tear fluid levels of antiRo/SSA and anti-La/SSB and clinical parameters of dry eye are presented in table 3. Serum anti-Ro/SSA and anti-La/SSB concentrations correlated with dry eye symptom scores $(r=0.42, \quad \mathrm{p}=0.02$ and $r=0.48, \mathrm{p}=0.01$, respectively $)$. Serum anti-Ro/SSA and anti-La/SSB levels showed an inverse correlation with Schirmer I test scores $(r=-0.39, \mathrm{p}=0.04$ and $r=-0.40, \mathrm{p}=0.03$, respectively). Significant correlations were found between tear anti-La/SSB concentrations and dry eye symptom score $(r=0.56, \mathrm{p}=0.002)$ and rose bengal staining scores of the ocular surface $(r=0.44, \mathrm{p}=0.02)$.

\section{DISCUSSION}

The clinical relevance of measuring IgG and $\operatorname{IgM}$ autoantibodies to Ro/SSA and La/SSB in the sera of patients with Sjögren's syndrome and systemic lupus erythematosus has been established over 20 years. ${ }^{19-21}$ More recently, Ro/SSA and $\mathrm{La} / \mathrm{SSB}$ specific IgA autoantibodies have also been shown in the sera of SS patients. ${ }^{22}$ As the salivary and lacrimal glands are the major target tissues in SS, it is logical to look for local synthesis of autoantibodies in these tissues. A number of studies investigated the presence of autoantibodies to Ro/SSA and La/SSB in saliva of SS patients, ${ }^{13-15}$ however we are unaware of previous studies in the tear fluid. In the present study, we investigated the presence of IgG antibodies against Ro/SSA and La/SSB antigens in the tear fluid and found that some of the SS patients had increased tear fluid levels of these autoantibodies. Domingo et $a^{23}$ reported increased levels of IgG in the tear fluid of rheumatoid arthritis patients 
Table 1 Anti-Ro/SSA and anti-La/SSB levels in serum and tear fluid of healthy controls and SS patients

\begin{tabular}{|c|c|c|c|c|c|c|c|c|c|c|c|c|}
\hline & \multicolumn{6}{|c|}{ Anti-Ro/SSA (U/ml) } & \multicolumn{6}{|c|}{ Anti-La/SSB (U/ml) } \\
\hline & \multicolumn{3}{|l|}{ Serum } & \multicolumn{3}{|l|}{ Tear fluid } & \multicolumn{3}{|l|}{ Serum } & \multicolumn{3}{|l|}{ Tear fluid } \\
\hline & $\begin{array}{l}\text { Controls } \\
(\mathrm{n}=17)\end{array}$ & $\begin{array}{l}\text { Primary } \\
\text { SS }(n=14)\end{array}$ & $\begin{array}{l}\text { Secondary } \\
\text { SS }(n=14)\end{array}$ & $\begin{array}{l}\text { Controls } \\
(\mathrm{n}=17)\end{array}$ & $\begin{array}{l}\text { Primary SS } \\
(n=14)\end{array}$ & $\begin{array}{l}\text { Secondary } \\
\text { SS }(n=14)\end{array}$ & $\begin{array}{l}\text { Controls } \\
(n=17)\end{array}$ & $\begin{array}{l}\text { Primary SS } \\
(n=14)\end{array}$ & $\begin{array}{l}\text { Secondary } \\
\text { SS }(n=14)\end{array}$ & $\begin{array}{l}\text { Controls } \\
(n=17)\end{array}$ & $\begin{array}{l}\text { Primary SS } \\
(n=14)\end{array}$ & $\begin{array}{l}\text { Secondary } \\
\text { SS }(n=14)\end{array}$ \\
\hline $\begin{array}{l}\text { Mean } \\
\text { (SD) }\end{array}$ & $13.1(7)$ & $81.9(82)$ & $37.7(40)$ & $12.4(6.4)$ & $27(30)$ & $15(7.9)$ & $18.4(6.4)$ & $60.3(60.2)$ & $41(38.2)$ & $17.9(6.6)$ & $43.8(54.4)$ & $24.5(38.2)$ \\
\hline Median & 12.5 & $39.3^{*}$ & 25.2 & 11.5 & 14.3 & 13.5 & 19.5 & $40.5 \dagger$ & 25.2 & 19 & 25.2 & 26 \\
\hline Range & $1.3-26.5$ & $1.4-256$ & $1.4-119.5$ & $1.1-23.9$ & $1.3-89.2$ & $1.6-28$ & $7.5-29.1$ & $19.2-237$ & $10.2-129.5$ & $7.5-29.9$ & $7.6-177.3$ & $8.1-51.9$ \\
\hline
\end{tabular}

*Significantly different from the control group $(p=0.003)$.

†Significantly different from the control group $(p=0.001)$

with secondary SS and that the levels of IgG correlated with the severity of dry eye. There are controversial results regarding the isotype of detected antibodies against Ro/SSA and La/SSB antigens in saliva of SS patients. Horsfall et al, ${ }^{13}$ reported salivary enrichment of mainly IgA and to a lesser extent of IgG La anti-idiotype antibodies and detection of salivary anti-La/SSB antibodies in SS patients who were negative for anti-La/SSB in their sera. Another study revealed salivary enrichment of IgA and IgM against Ro and La antigens and IgG against La antigen in about one third of the patients with SS. ${ }^{15}$ Two recent studies demonstrated anti-Ro and anti-La producing lymphocytes in the salivary glands providing a direct evidence of local production. One of these studies showed that the anti-Ro/SSA and anti-La/SSB producing cells contained antibodies of predominantly IgA type, and to a lesser extent, IgG or IgM type. ${ }^{16}$ On the contrary, the other study demonstrated that labial salivary gland lymphocytes of SS patients produced antibodies to Ro/ SSA antigen mainly of the IgG isotype. ${ }^{17}$

In the present study, serum and tear fluid levels of anti-Ro/ SSA correlated strongly with that of anti-La/SSB, as was reported previously. ${ }^{24}$ This might be explained by the fact that

Table 2 Objective and subjective clinical scores of dry eye in SS patients and controls (mean (SD))

\begin{tabular}{|c|c|c|c|}
\hline & $\begin{array}{l}\text { Primary SS } \\
\text { patients }\end{array}$ & $\begin{array}{l}\text { Secondary } \\
\text { SS patients }\end{array}$ & Controls \\
\hline & $(n=14)$ & $(n=14)$ & $(n=17)$ \\
\hline Schirmer I test $(\mathrm{mm})$ & $4.0(2.8)$ & $4.3(3.2)$ & $15.4(4.6)$ \\
\hline Tear break up time (sec) & $2.3(2.0)$ & $3.5(1.9)$ & $12.8(5.7)$ \\
\hline Rose bengal staining score & $4.6(1.7)$ & $4.4(1.2)$ & $0.17(0.39$ \\
\hline Dry eye symptom score & $5.6(3.0)$ & $4.3(2.9)$ & 0.0 \\
\hline
\end{tabular}

Table 3 Correlations between objective and subjective clinical dry eye scores and levels of autoantibodies in serum and tear fluid of SS patients

\begin{tabular}{|c|c|c|c|c|c|}
\hline & & \multicolumn{2}{|c|}{ Anti-Ro/SSA } & \multicolumn{2}{|c|}{ Anti-La/SSB } \\
\hline & & Serum & Tear & Serum & Tear \\
\hline Schirmer I test & $r$ & $\begin{array}{l}-0.39 \\
0.04\end{array}$ & -0.05 & $\begin{array}{l}-0.40 \\
0.03\end{array}$ & -0.34 \\
\hline Tear break up time & $r$ & 0.28 & 0.19 & 0.19 & -0.15 \\
\hline Rose bengal staining & $\begin{array}{l}\mathrm{p} \\
\mathrm{r}\end{array}$ & $\begin{array}{l}\text { ns } \\
0.31\end{array}$ & $\begin{array}{l}\text { ns } \\
0.34\end{array}$ & $\begin{array}{l}\text { ns } \\
0.07\end{array}$ & $\begin{array}{l}\text { ns } \\
0.44\end{array}$ \\
\hline Dry eye symptom score & $\begin{array}{l}\mathrm{p} \\
r \\
\mathrm{p}\end{array}$ & $\begin{array}{l}\text { ns } \\
0.42 \\
0.02\end{array}$ & $\begin{array}{l}\text { ns } \\
0.31 \\
\text { ns }\end{array}$ & $\begin{array}{l}\text { ns } \\
0.48 \\
0.01\end{array}$ & $\begin{array}{l}0.02 \\
0.56 \\
0.002\end{array}$ \\
\hline
\end{tabular}

r, Spearman correlation coefficient; ns, not significant. the La/SSB antigen is, in part, physically associated with the Ro RNP particle, providing a macromolecular target for the linked set of anti-Ro and anti-La antibodies. ${ }^{25}{ }^{26}$ The detection of autoantibodies to Ro/SSA and La/SSB in the tear fluid may result from extravasation of proteins from blood vessels into inflamed lacrimal gland tissue or it may reflect local synthesis from autoantibody producing cells in the lacrimal gland. Although the frequency of detection of these autoantibodies in the tear fluid of patients with SS was lower compared with the frequency of serum positivity, a number of patients who were negative for either of these autoantibodies in serum had elevated levels in the tear fluid. Furthermore, although we found a weak association between serum and tear titres of anti-Ro/SSA, the tear fluid level of anti-La/SSB was independent of serum levels. Taken together, these results may present indirect evidence of local production of these autoantibodies in the lacrimal gland. Therefore, measurement of these antibodies in the tear fluid in addition to sera may be helpful in the diagnosis of the disease.

The contribution of Ro/SSA and La/SSB specific autoantibodies to the pathogenesis of SS remains unclear. The presence of these antibodies in serum is associated, in particular with earlier disease onset and longer disease duration, extraglandular disease manifestations (splenomegaly, lymphadenopathy, vasculitis, purpura), recurrent parotid gland enlargement and lymphocytic infiltration of labial salivary glands..$^{27-30}$ Pourmand et al ${ }^{22}$ reported a weak correlation between the serum titres of antibodies of IgA subclass against Ro/SSA and La/SSB antigens and oral and ocular sicca symptoms. A strong relation between local inflammation of the salivary glands and autoantibody titres in saliva has also been shown. ${ }^{15}$ In the present study, serum titre of anti-Ro/SSA and anti-La/SSB correlated positively with dry eye symptoms and negatively with tear production, and tear titre of anti-La/SSB correlated positively with dry eye symptoms and the severity of ocular surface staining. These findings suggest the possible contribution of these autoantibodies, particularly local presence of anti-La/SSB to the pathogenesis of exocrinopathy in SS.

In summary, we have demonstrated the presence of Ro/ SSA and La/SSB specific antibodies in the tear fluid of SS patients, and that they can even be detected in the tear fluid of patients with negative serum titres. It seems reasonable to suggest that additional measurement of these autoantibodies in the tear fluid may be helpful in the diagnosis of SS and may even be useful in the evaluation of treatment outcomes. The results of this study also revealed the association of these autoantibodies with the severity of ocular disease. Further studies with larger numbers of patients which also investigate the presence of other isotypes (IgA and $\operatorname{IgM}$ ) are needed to further elucidate the contribution of these local autoantibodies to the pathogenesis and diagnosis of the disease. 


\section{Authors' affiliations}

E Toker, Department of Ophthalmology, Marmara University, School of Medicine, Marmara, Turkey

Ș Yavuz, H Direskeneli, Department of Rheumatology, Marmara University, School of Medicine, Marmara, Turkey

\section{REFERENCES}

1 Chan EK, Tan EM. Epitopic targets for autoantibodies in SLE and Siögren's syndrome. Curr Opin Rheumatol 1989;1:376-81.

2 Ben-Chetrit E, Gandy BJ, Tan EM, et al. Isolation and characterization of cDNA clone encoding the $60 \mathrm{kD}$ component of the human SS-A/Ro ribonucleoprotein autoantigen. J Clin Invest 1989:83:1284-92.

3 O'Brien CA, Margelot K, Wolin SE. Xenopus Ro ribonucleoproteins: members of an evolutionary conserved class of cytoplasmic ribonucleoproteins. Proc Natl Acad Sci U S A 1993;90:7250-4.

4 Ben-Chetrit E, Chan EK, Sullivan KF, et al. A $52-\mathrm{kD}$ protein is a novel component of the SS-A/Ro antigenic particle. J Exp Med 1988;167:1560-71.

5 Boire G, Gendron M, Monast N, et al. Purification of antigenically intact Ro ribonucleoproteins: biochemical and immunological evidence that the 52-kD protein is not a Ro protein. Clin Exp Immunol 1995;100:489-98.

6 Kelekar A, Saitta MR, Keene JD. Molecular composition of Ro small ribonucleoprotein complexes in human cells-intracellular localization of the 60- and 52-kD proteins. J Clin Invest 1994:93:1637-44.

7 O'Brien CA, Wolin SL. A possible role for the 60-kD Ro autoantigen in a discard pathway for defective 5 S RNA precursors. Gene Dev 1994;8:2891-903.

8 Rinke J, Steitz JA. Precursor molecules of both human 5S ribosomal RNA and transfer RNAs are bound by a cellular protein reactive with anti-La lupus antibodies. Cell 1982;29:149-59.

9 Gottlieb E, Steitz JA. Function of the mammalian La protein: evidence for its action in transcription termination by RNA polymerase III. EMBO J 1989:8:851-61.

10 Stefano JE. Purified lupus antigen La recognizes an oligo uridylate stretch common to the $3^{\prime}$ termini of RNA polymerase III transcripts. Cell 1984:36:145-54

11 Vitali C, Bombardieri S, Moutsopoulos HM, et al. Preliminary criteria for the classification of Sïgren's syndrome. Arthritis Rheum 1993;36:340-7.

12 Tan EM. Antinuclear antibodies: diagnostic markers for autoimmune diseases and probes for cell biology. Adv Immunol 1989:44:93-106.

13 Horsfall AC, Rose LM, Maini RN. Autoantibody synthesis in the salivary glands of Sïgren's syndrome patients. J Autoimmun 1989;2:559-68.

14 Ben-Chetrit E, Fischel R, Rubinow A. Anti-SSA/Ro and anti-SSB/La antibodies in serum and saliva of patients with Sjögren's syndrome. Clin Rheumatol 1993;12:471-4.
15 Halse A-K, Marthinussen MC, Wahren-Herlenius M, et al. Isotype distribution of anti-Ro/SS-A and anti-La/SS-B antibodies in plasma and saliva of patients with Siögren's syndrome. Scan J Rheumatol 2000;29:13-19.

16 Tegner $\mathrm{P}$, Halse A-K, Haga H-J, et al. Detection of anti-Ro/SSA and anti-La/ SSB autoantibody producing cells in salivary glands from patients with Siögren's syndrome. Arthritis Rhem 1998;41:2238-48

17 Halse A-K, Harley JB, Kroneld U, et al. Ro/SS-A reactive B lymphocytes in salivary glands and peripheral blood of patients with Sjögren's syndrome. Clin Exp Immunol 1999;1 15:203-7.

18 Bijsterveld O, Holland U. Diagnostic tests in sicca syndrome. Arch Ophthalmol 1969;82:10-14.

19 Alpspaugh MA, Talal N, Tan EM. Differentiation and characterization of autoantibodies and their antigens in Sjögren's syndrome. Arthritis Rheum 1976:19:216-22.

20 Lindstrom FD, Eriksson P, Tejle K, et al. IgG subclasses of anti-SS-A/Ro in patients with primary Siögren's syndrome. Clin Immunol Immunopathol 1994:73:358-361.

21 Wahren M, Ringertz NR, Pettersson I. IgM and lgG subclass distribution of human anti-Ro/SSA $60 \mathrm{kDa}$ autoantibodies. Scand J Immunol 1994;39:179-83.

22 Pourmand N, Wahren-Herlenius M, Gunnarsson I, et al. Ro/SSA and La/SSB specific IgA antibodies in serum of patients with Sïgren's syndrome and systemic lupus erythematosus. Ann Rheum Dis 1999;58:623-9.

23 Domingo I, Coll J, Montobio J, et al. Lacrimal immunoglobulins in rheumatoid arthritis patients with or without Sjögren's syndrome. Ophthalmologica 1998;212:30-3.

24 Harley JB, Alexander EL, Bias WB, et al. Anti-Ro(SS-A) and anti-La(SS-B) in patients with Siögren's syndrome. Arthritis Rheum 1986;29:196-206.

25 Hendrick JP, Wolin SL, Rinke J, et al. Ro small cytoplasmic ribonucleoproteins are a subclass of La ribonucleoproteins: further characterization of the Ro and La small ribonucleoproteins from uninfected mammalian cells. Mol Cell Biol 1981;1:1138-49.

26 Boire G, Craft J. Human Ro ribonucleoprotein particles: characterization of native structure and stable association with the La polypeptide. J Clin Invest 1990;85:1182-90.

27 Manoussakis MN, Tzioufas AG, Pange PJ, et al. Serologic profiles in subgroups of patients with Siögren's syndrome. Scan J Rheumatol Suppl 1986;61:89-92.

28 Alexander EL, Arnett FC, Provost TT, et al. Siögren's syndrome: association of anti-Ro(SS-A) antibodies with vasculitis, hematologic abnormalities, and serologic hyperactivity. Ann Intern Med 1983:98:155-9.

29 Gerli R, Muscat C, Giansanti M, et al. Quantitative assessment of salivary gland inflammatory infiltration in primary Sjögren's syndrome: its relationship to different demographic, clinical and serological features of the disorder. Br J Rheumatol 1997;36:969-75.

30 Nakamura S, Ikebe-Hiroki A, Shinohara M, et al. An association between salivary gland disease and serological abnormalities in Siögren's syndrome. J Oral Pathol Med 1997;26:426-30. 